\title{
Oncological Outcomes of Open Radical Retropubic Prostatectomy in Ireland: A Single Surgeon's 5-Year Experience
}

\author{
Stefanie M. Croghan, MRCSI ${ }^{1}$ Deep Mudit Matanhelia, MRCSI ${ }^{2}$ Ann T. Foran, MRCSI ${ }^{1}$ \\ David J. Galvin, FRCS Urol ${ }^{1,2,3}$ \\ ${ }^{1}$ Department of Urology, The Mater Misericordiae University \\ Hospital, Eccles Street, Dublin, Ireland \\ 2 Department of Urology, St. Vincent's University Hospital, Elm Park, \\ Dublin, Ireland \\ ${ }^{3}$ Department of Urology, St. Vincent's Private Hospital, Elm Park, \\ Dublin, Ireland \\ Surg J 2018;4:e226-e234.

\begin{abstract}
Address for correspondence Stefanie M. Croghan, MRCSI, Department of Urology, St. Vincent's University Hospital, Elm Park, Dublin 8, Ireland (e-mail: croghans@tcd.ie).
\end{abstract}

\begin{abstract}
Objectives There is a little published data on the outcomes of radical prostatectomy in the Irish context. We aimed to determine the 5-year oncological results of open radical retropubic prostatectomy (RRP) performed by a single surgeon following appointment. Methods A retrospective review of RRPs performed between 2011 and 2016 was conducted. Patient demographics, preoperative parameters (clinical stage on digital rectal exam, prostate-specific antigen (PSA) levels, biopsy Gleason's score and MRI [magnetic resonance imaging] findings), pathological variables (T-stage, Gleason's score, nodal status, and surgical margin status), and treatment decisions (lymphadenectomy or adjuvant radiotherapy) were recorded. Oncological outcome at last follow-up was ascertained.

Results 265 patients underwent RRP between 2011 and 2016. Median age was 62 years (range: 41-74). Mean follow-up was 32.24 months (range: 8-72) months. Pathological disease stage was T2 in 170/265 (64.15\%), T3a in 65/265 (24.53\%), and T3b in 30/265 (11.32\%). Final Gleason's score was upgraded from diagnostic biopsy in 16.35\% (43/263) and downgraded in $27 \%$ (71/263). Pelvic lymph node dissection was performed in $44.25 \%$

\section{Keywords}

- radical retropubic prostatectomy

- RRP

- open prostatectomy

- prostate cancer

- oncological outcomes $(118 / 265)$ patients. A positive surgical margin (PSM) was seen in $26 / 170$ (15.2\%) patients with T2 disease and in 45/95 (47.37\%) patients with T3 disease. Of the 265 patients, 238 $(89.81 \%)$ were disease-free at last follow-up, of whom $24 / 238(10.08 \%)$ had received adjuvant and $17 / 238(7.14 \%)$ received salvage radiotherapy. Adjuvant/salvage treatment was ongoing in 19/265 (7.17\%) of patients.

Conclusion Good oncological outcomes of RRP in the Irish context are seen in this 5year review, with the vast majority of patients experiencing biochemical-free survival at most recent follow-up.
\end{abstract}

Prostate cancer is reported to be the most common invasive cancer affecting both Irish and European men overall (excluding non-melanoma skin cancers). ${ }^{1,2}$ Over 3,400 Irish men are diagnosed per annum, with National Cancer Registry Ireland (NCRI) figures estimating that $28 \%$ of men proceed to surgical treatment within a year of diagnosis (2012-2014). ${ }^{3}$ This figure has been steadily increasing and may in part reflect a trend toward early-stage diagnosis facilitated by Rapid Access Prostate Cancer Clinics (RAPCs) ${ }^{4}$ which were established in eight national cancer centers received

July 29, 2018

accepted after revision

October 8, 2018
DOI https://doi.org/

$10.1055 / \mathrm{s}-0038-1675827$. ISSN $2378-5128$.
Copyright $\odot 2018$ by Thieme Medical

Publishers, Inc., 333 Seventh Avenue, New York, NY 10001, USA. Tel: +1(212) 584-4662.
License terms

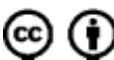


following the Irish National Cancer Control Program (NCCP), National Strategy for Cancer Control 2006. ${ }^{5}$

While radical prostate surgery has evolved greatly over the past decade, with a variety of techniques now established in urological practice, open radical prostatectomy remains a common procedure. Surprisingly, however, there is a paucity of data regarding Irish outcomes of this approach.

The aim of the present study was to evaluate the oncological outcomes of patients undergoing open radical retropubic prostatectomy (RRP) performed by a single surgeon across three centers in Ireland.

\section{Methods}

All patients who underwent open RRP, with or without pelvic lymph node dissection (PLND), performed by a single surgeon (D.J.G.) between September 2011 and November 2016 were included. Surgery was performed on one of three sitesThe Mater Misericordiae University Hospital, St. Vincent's University Hospital, and St. Vincent's Private Hospital, all located in Dublin, Ireland.

Our practice is to offer surgical treatment to all patients with non-metastatic prostate cancer considered fit for surgery, having counseled them as to alternative options, including radiotherapy (with external beam radiotherapy or brachytherapy discussed by a radiation oncologist) and, where appropriate, active surveillance (AS). The absence of metastatic disease is confirmed on clinical assessment and radiological staging with multiparametric MRI prostate with additional isotope bone scan $+/-$ CT (computed tomography) TAP (thorax abdomen pelvis) in patients with Gleason score $>7$ on biopsy or prostate-specific antigen (PSA) $\geq 10 \mathrm{mg}$.

The decision to perform pelvic lymph node dissection (PLND) is based on preoperative predicted rates of lymph node positivity, for which we routinely use Memorial Sloan Kettering Cancer Centre (MSKCC) nomograms, ${ }^{6}$ proposing PLND to patients in categories with $\geq 5 \%$ estimated rates of nodal positivity. The form of lymphadenectomy performed during the study period was standard PLND, comprising obturator and external iliac nodal basins with extended nodal dissection (ePLND) performed on selected patients (generally prompted by young age or significant burden of high grade disease). A nerve-sparing approach is attempted where clinical staging (taking into account preoperative imaging and intraoperative findings) is estimated at $\leq \mathrm{T} 2$; patients with $\geq \mathrm{T} 3$ diseases are considered for a unilateral nerve-sparing approach on the contralateral side in cases where extracapsular extension is appreciated on one side of the gland only.

All patients are discussed postoperatively at a urology multidisciplinary team (MDT) meeting, with decision for further treatment, primarily adjuvant radiotherapy, made in this forum. Standard follow-up comprises clinical review with a PSA reading at 3-months and then 6 monthly for 2 years, assuming biochemical recurrence is not detected. Annual PSA monitoring is adopted thereafter.

A retrospective electronic chart review of all patients was performed. Preoperatively recorded data included: patient age at diagnosis, clinical stage on digital rectal exam, preoperative prostate-specific antigen (PSA) level, Gleason's score and number of positive cores at transrectal ultrasound guided (TRUS) biopsy, and modality and results of imaging performed for radiological staging. The date of surgery and decision regarding the need to perform PLND was documented. Final histopathological results were reviewed with pathological Tstage, Gleason's score, nodal status, and surgical margin status recorded. Surgical margin status was defined as the presence of tumor at the inked surface of the specimen ${ }^{7}$ and classified as focal $(\leq 3 \mathrm{~mm}$ ) or extensive ( $\geq 3 \mathrm{~mm}$ or multifocal) based on stratification proposed by other authors. ${ }^{8,9}$ All patients' oncological outcome was ascertained by review of PSA at last follow-up, and/or imaging findings were relevant. Where a PSA value within the previous 12 months was not available from the chart, an attempt to obtain more recent follow-up data was made by telephoning the patient's general practitioner. Biochemical recurrence was defined as two rising PSA readings $\geq 0.05$. Postoperative radiotherapy was defined as adjuvant if the decision to administer radiotherapy was made at the postoperative MDT meeting (in which case treatment was typically commenced at 4 to 6 months postoperatively) and as salvage if the patient was referred for radiotherapy in response to rising PSA levels where the MDT decision had been for surveillance in the first instance.

\section{Results}

A total of 265 patients underwent open RRP in the study period between 2011 and 2016. Mean age at diagnosis was 61.26 years (range: 41-74 years). Disease characteristics (Gleason's score on TRUS biopsy and PSA at diagnosis) are shown in - Table 1. The majority of our patients (182/265, 68.68\%) had Gleason's score 7 disease. Overall, the mean PSA at diagnosis was 9.46 (range: 1.06-76.7). Follow-up is outlined in - Table 2.

Distribution of Gleason's score, including numbers upstaged or downstaged from TRUS biopsy diagnosis in final histology and T-stage across our patient population is outlined in - Table 3.

A pelvic lymph node dissection was performed in 118/265 (44.25\%) with mean number of nodes retrieved 6.08 (range: 122). Lymphadenectomy data are outlined in - Table 4. Of 104 patients staged pNO (pathologically node negative), 4 had had radiological suspicion of nodal involvement preoperatively. Of

Table 1 Age and preoperative disease characteristics

\begin{tabular}{|l|l|l|}
\hline Median age & \multicolumn{2}{|l|}{62 y (range: $41-74$ y) } \\
\hline $\begin{array}{l}\text { Gleason's } \\
\text { (TRUS biopsy) }\end{array}$ & $\mathrm{n}(\%)$ & $\begin{array}{l}\text { Mean PSA at } \\
\text { diagnosis }\end{array}$ \\
\hline 6 & $28(10.56)$ & $8.82(3.7-35.2)$ \\
\hline 7 & $139(52.45)$ & $8.62(1.06-29)$ \\
\hline 8 & $72(27.38)$ & $10.22(2.7-76.7)$ \\
\hline 9 & $23(8.68)$ & $13.19(3-41)$ \\
\hline 10 & $3(1.13)$ & $6.89(6.5-7.15)$ \\
\hline
\end{tabular}

Abbreviations: PSA, prostate-specific antigen; TRUS, trans-rectal ultrasound. 
Table 2 Follow-up timeframe

\begin{tabular}{|l|l|}
\hline Follow-up \\
\hline Mean overall follow-up & 32.24 months (8-72) \\
\hline $\begin{array}{l}\text { Mean follow-up post } \\
\text { salvage radiotherapy }\end{array}$ & 25.95 months (1-55) \\
\hline
\end{tabular}

Table 3 Final histopathology

\begin{tabular}{|l|l|l|}
\hline \multicolumn{2}{|l|}{ Histopathology } & $\boldsymbol{n}=265(\%)$ \\
\hline score & 6 & $23(8.68)$ \\
\cline { 2 - 3 } & 7 & $182(68.68)$ \\
\cline { 2 - 3 } & 8 & $29(10.94)$ \\
\cline { 2 - 3 } & 9 & $30(11.32)$ \\
\cline { 2 - 3 } & 10 & $1(0.38)$ \\
\hline & $\begin{array}{l}\text { Gleason's } \\
\text { upstaged }\end{array}$ & $43 / 263(16.35)$ \\
\cline { 2 - 3 } & $\begin{array}{l}\text { Gleason's } \\
\text { downstaged }\end{array}$ & $71 / 263(27)$ \\
\hline Pathological & T2a & $22(8.30)$ \\
\hline & T2b & $9(3.4)$ \\
\cline { 2 - 3 } & T2c & $139(52.45)$ \\
\cline { 2 - 3 } & T3a & $65(24.53)$ \\
\cline { 2 - 3 } & T3b & $30(11.32)$ \\
\hline
\end{tabular}

these four patients, three received no additional therapy and one received adjuvant radiotherapy; all four were disease-free at last follow-up.

The overall rate of positive surgical margins (PSMs) was $26.79 \%(71 / 265)$. As related to T-stage, PSMs were observed in $26 / 170(15.2 \%)$ of T2 disease (focal in 19/26 [73.07\%]) and in $45 / 95$ (47.37\%) of T3 disease (focal in 27/45 [60\%]). - Table 5 describes details of surgical margin status.

At most recent follow-up, 238/265 (89.81\%) of patients were disease-free of whom $24 / 238$ (10.08\%) had received adjuvant and 17/238 (7.14\%) received salvage radiotherapy,
Table 5 Breakdown of surgical margin status

\begin{tabular}{|c|c|c|}
\hline \multicolumn{3}{|c|}{$\mathrm{T} 2(n=170)$} \\
\hline \multicolumn{3}{|c|}{ Positive surgical margin: $15.2 \%(26 / 170)$} \\
\hline pT stage & \multicolumn{2}{|c|}{ Margin status by stage } \\
\hline \multirow{3}{*}{$\begin{array}{l}\text { T2a } \\
(n=22)\end{array}$} & R0 & $90.9 \%(20 / 22)$ \\
\hline & R1 (focal) & $9.09 \%(2 / 22)$ \\
\hline & R1 (extensive) & - \\
\hline \multirow{3}{*}{$\begin{array}{l}\text { T2b } \\
(n=9)\end{array}$} & R0 & $88.89 \%(8 / 9)$ \\
\hline & R1 (focal) & - \\
\hline & R1 (extensive) & $11.12 \%(1 / 9)$ \\
\hline \multirow{3}{*}{$\begin{array}{l}\text { T2c } \\
(n=139)\end{array}$} & R0 & $83.45 \%(116 / 139)$ \\
\hline & R1 (focal) & $12.23 \%(17 / 139)$ \\
\hline & R1 (extensive) & $4.32 \%(6 / 139)$ \\
\hline \multicolumn{3}{|c|}{ T3 $(n=95)$} \\
\hline \multicolumn{3}{|c|}{ Positive Surgical Margin: 47.37\% (45/95) } \\
\hline pT Stage & \multicolumn{2}{|c|}{ Margin status by stage } \\
\hline \multirow{3}{*}{$\begin{array}{l}\text { T3a } \\
(n=65)\end{array}$} & R0 & $52.3 \%(34 / 65)$ \\
\hline & R1 (focal) & $27.7 \%(18 / 65)$ \\
\hline & R1 (extensive) & $20 \%(13 / 65)$ \\
\hline \multirow{3}{*}{$\begin{array}{l}\text { T3b } \\
(n=30)\end{array}$} & R0 & $53.34 \%(16 / 30)$ \\
\hline & R1 (focal) & $30 \%(9 / 30)$ \\
\hline & R1 (extensive) & $16.67 \%(5 / 30)$ \\
\hline
\end{tabular}

and no patients had died of prostate cancer. Of the overall cohort, 33/265 (12.45\%) of patients received adjuvant therapy. Of patients that did not receive adjuvant therapy up front $(n=232), 32$ patients $(13.79 \%)$ were ultimately referred for salvage therapy. Either adjuvant or salvage treatment (radiotherapy or androgen deprivation therapy) was ongoing in 19/265 (7.17\%) of patients. Mean overall follow-up was 32.24 months (range: 8-72 months).

Overall oncological outcomes relative to preoperative PSA, pathological T and N-stage, final Gleason's score and surgical margin status are outlined in -Tables 6-8.

Table 4 Lymphadenectomy data

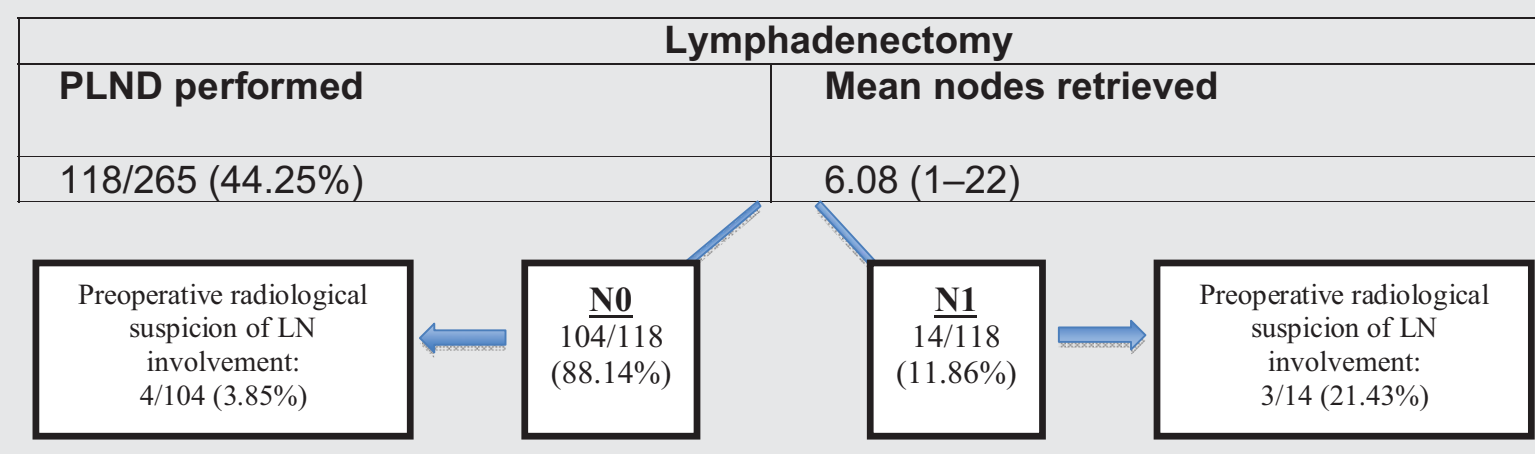

Abbreviations: PLND, pelvic lymph node dissection; LN, lymph node. 
Table 6 Outcomes of PT2 disease

\begin{tabular}{|c|c|c|c|c|c|c|c|c|c|c|c|}
\hline pT stage & $\begin{array}{l}\text { Gleason's } \\
\text { score }\end{array}$ & \multicolumn{2}{|l|}{ Treatment } & Mean PSA & PLND & $\begin{array}{l}\text { N1 status } \\
\text { (of PLND) }\end{array}$ & $\begin{array}{l}\text { PSM } \\
\text { (R1) }\end{array}$ & $\begin{array}{l}\text { Disease- } \\
\text { free }\end{array}$ & $\begin{array}{l}\text { Alive } \\
\text { with }\end{array}$ & $\begin{array}{l}\text { Treatment } \\
\text { ongoing }^{*}\end{array}$ & Others \\
\hline \multirow[t]{8}{*}{$\begin{array}{l}\text { T2 } \\
(n=170)\end{array}$} & \multirow[t]{3}{*}{$\begin{array}{l}6 \\
(n=22)\end{array}$} & $\begin{array}{l}\text { Surgery } \\
\text { alone }\end{array}$ & $22 / 22$ & - & - & - & - & $21 / 22$ & $0 / 22$ & - & $\begin{array}{l}1 / 22 \text { died } \\
\text { unrelated }\end{array}$ \\
\hline & & + Adjuvant & - & - & - & - & - & - & - & - & - \\
\hline & & + Salvage & - & - & - & - & - & - & - & - & - \\
\hline & \multirow[t]{4}{*}{$\begin{array}{l}7 \\
(n=129)\end{array}$} & $\begin{array}{l}\text { Surgery } \\
\text { alone }\end{array}$ & $116 / 129$ & $\begin{array}{l}8.22 \\
(1.06-29)\end{array}$ & $29 / 116$ & $0 / 29$ & $14 / 116$ & $114 / 116$ & - & - & $\begin{array}{l}1 / 116 \text { lost to } \\
\text { follow-up } \\
1 / 116 \text { died } \\
\text { unrelated }\end{array}$ \\
\hline & & + Adjuvant & $4 / 129$ & $\begin{array}{l}7.77 \\
(4.6-12.8)\end{array}$ & $2 / 4$ & $0 / 2$ & $3 / 4$ & $4 / 4$ & - & - & - \\
\hline & & + Salvage & $9 / 129$ & $\begin{array}{l}9.7 \\
(5.8-15.1)\end{array}$ & $2 / 9$ & $0 / 2$ & $4 / 9$ & $6 / 9$ & - & $3 / 6$ & - \\
\hline & & \multicolumn{10}{|c|}{$>$ Mean time to BCR (mo): $14(3-39)$} \\
\hline & \multirow[t]{4}{*}{$\begin{array}{l}8 \\
(n=11)\end{array}$} & $\begin{array}{l}\text { Surgery } \\
\text { alone }\end{array}$ & $8 / 11$ & $\begin{array}{l}8.28 \\
(2.7-15)\end{array}$ & $7 / 8$ & $0 / 7$ & $3 / 8$ & $8 / 8$ & - & - & - \\
\hline \multirow[t]{8}{*}{-} & & + Adjuvant & - & - & - & - & - & - & - & - & - \\
\hline & & + Salvage & $3 / 11$ & $\begin{array}{l}5.6 \\
(4-8.6)\end{array}$ & $2 / 3$ & $0 / 2$ & $0 / 3$ & $3 / 3$ & - & - & - \\
\hline & & \multicolumn{10}{|c|}{$>$ Mean time to BCR (mo): 20 (7-27) } \\
\hline & \multirow[t]{4}{*}{$\begin{array}{l}9 \\
(n=7)\end{array}$} & $\begin{array}{l}\text { Surgery } \\
\text { alone }\end{array}$ & $4 / 7$ & $\begin{array}{l}11.38 \\
(4.3-26.3)\end{array}$ & $3 / 4$ & $0 / 3$ & $0 / 4$ & $4 / 4$ & - & - & - \\
\hline & & + Adjuvant & $1 / 7$ & 7 & $1 / 1$ & $0 / 1$ & $1 / 1$ & $1 / 1$ & - & - & - \\
\hline & & + Salvage & $2 / 7$ & $\begin{array}{l}10.4 \\
(10-10.8)\end{array}$ & $1 / 2$ & $1 / 1$ & $0 / 2$ & $1 / 2$ & - & $1 / 2$ & - \\
\hline & & \multicolumn{10}{|c|}{$>$ Mean time to BCR (mo): 23.5 (5-42) } \\
\hline & $\begin{array}{l}10 \\
(n=1)\end{array}$ & + Adjuvant & $1 / 1$ & 6.3 & $1 / 1$ & $1 / 1$ & $0 / 1$ & $1 / 1$ & - & - & - \\
\hline
\end{tabular}

Abbreviations: BCR, biochemical recurrence; PSA, prostate-specific antigen; PLND, pelvic lymph node dissection; PSM, positive surgical margin.

\section{Discussion}

To date, there has been a paucity of data pertaining to outcomes of radical prostatectomy in Ireland. The only other recently published paper relating to overall outcomes of Irish prostatectomy assesses results of 125 consecutive robot assisted cases with excellent early outcomes at 1 year. ${ }^{10}$ Open RRP, however, remains a common operation outside of robotic centers in North America and Europe, and debate continues as to whether an open or robotic approach to radical prostatectomy confers a clear benefit in oncological or functional outcomes. ${ }^{11}$ As such, we feel continued publication of open RRP results is both relevant and necessary, and hope that our experience contributes to the gap in the Irish outcomes literature.

Mean PSA at diagnosis for all groups was $9.46 \mathrm{ng} / \mathrm{mL}$ (range: $1.06-76.7 \mathrm{ng} / \mathrm{mL}$ ). This is largely congruent with the mean PSA at diagnosis reported by other authors (mean: 5.4 $\mathrm{ng} / \mathrm{mL}$ [range: $0.2-66 \mathrm{ng} / \mathrm{mL}$ ], ${ }^{12}$ median $5.6 \mathrm{ng} / \mathrm{mL},{ }^{13}$ mean $11.6 \mathrm{ng} / \mathrm{mL}$ [standard deviation (SD) 12.4$]^{14}$ ) although we note the width of our reported range. While we did not analyze data prior to the local establishment of Rapid Access Prostate Cancer Clinics, it has been previously recognized that these have led to prostate cancer diagnosis at lower mean PSA readings in the Irish population. ${ }^{4}$
With regard to preoperative cancer grading, based on diagnostic trans-rectal ultrasound (TRUS) biopsy, the majority of our RRP patients $(139 / 265,52.4 \%)$ were categorized as harboring Gleason's score $7(3+4$ or $4+3)$ disease, followed by Gleason's score $8(27.38 \%, n=72)$. Only a minority $(28 / 265,10.56 \%)$ carried a preoperative diagnosis of Gleason's score 6 disease. We note a different pattern in the literature, with a predominance of patients with preoperative Gleason's scores $\leq 6$ in cohorts undergoing RRP, as outlined in - Fig. 1. . $^{12-16}$

This may reflect higher grade disease at presentation, an aggressive surgical approach where all high risk patients with nonmetastatic disease are offered surgery and/or the fact that a large proportion of patients with Gleason's 6 disease at our institutions meet the criteria for active surveillance (AS) protocols, and it is the senior author's practice to offer AS to such patients, reflecting a shift in management strategy from that employed in historical series.

Discordance between Gleason score based on diagnostic TRUS biopsy and that reported from the prostatectomy specimen is a recognized phenomenon. Predictors described include the number of biopsy cores and prostate weight, ${ }^{17}$ the PSA density ${ }^{18}$ and the reporting of the specimen by a uropathologist. ${ }^{19}$ The international literature suggests an overall upgrading rate of 29 to $50.5 \%$ and an overall downgrading 
Table 7 Outcomes of pT3a disease

\begin{tabular}{|c|c|c|c|c|c|c|c|c|c|c|}
\hline pT stage & $\begin{array}{l}\text { Gleason's } \\
\text { score }\end{array}$ & \multicolumn{2}{|l|}{ Treatment } & Mean PSA & PLND & $\begin{array}{l}\text { N1 status } \\
\text { (of PLND) }\end{array}$ & $\begin{array}{l}\text { PSM } \\
\text { (R1) }\end{array}$ & $\begin{array}{l}\text { Disease- } \\
\text { free }\end{array}$ & $\begin{array}{l}\text { Alive with } \\
\text { disease }\end{array}$ & $\begin{array}{l}\text { Treatment } \\
\text { ongoing }^{\mathrm{a}}\end{array}$ \\
\hline $\begin{array}{l}\text { T3a } \\
(n=65)\end{array}$ & \multirow[t]{3}{*}{$\begin{array}{l}6 \\
(n=1)\end{array}$} & $\begin{array}{l}\text { Surgery } \\
\text { alone }\end{array}$ & $1 / 1$ & 5 & $0 / 1$ & - & $0 / 1$ & $1 / 1$ & - & - \\
\hline \multirow[t]{14}{*}{-} & & + Adjuvant & - & - & - & - & - & - & - & - \\
\hline & & + Salvage & - & - & - & - & - & - & - & - \\
\hline & \multirow[t]{4}{*}{$\begin{array}{l}7 \\
(n=40)\end{array}$} & $\begin{array}{l}\text { Surgery } \\
\text { alone }\end{array}$ & $31 / 40$ & $\begin{array}{l}8.03 \\
(3-18.12)\end{array}$ & $13 / 40$ & $0 / 13$ & $11 / 31$ & $31 / 31$ & - & - \\
\hline & & + Adjuvant & $2 / 40$ & $\begin{array}{l}8.1 \\
(6.1-10.1)\end{array}$ & $2 / 2$ & $0 / 2$ & $2 / 2$ & $2 / 2$ & - & - \\
\hline & & + Salvage $^{\wedge}$ & $7 / 40$ & $\begin{array}{l}9.98 \\
(4.1-16.8)\end{array}$ & $5 / 7$ & $0 / 5$ & $5 / 7$ & $3 / 7$ & - & $4 / 7$ \\
\hline & & \multicolumn{9}{|c|}{ ^Mean time to BCR (mo): 20 (5-40) } \\
\hline & \multirow[t]{4}{*}{$\begin{array}{l}8 \\
(n=10)\end{array}$} & $\begin{array}{l}\text { Surgery } \\
\text { alone }\end{array}$ & $4 / 10$ & $\begin{array}{l}7.3825 \\
(6.4-9.48)\end{array}$ & $4 / 4$ & $0 / 4$ & $1 / 4$ & $4 / 4$ & - & - \\
\hline & & + Adjuvant & $4 / 10$ & $\begin{array}{l}20.42 \\
(8-35.2)\end{array}$ & $3 / 4$ & $2 / 3$ & $4 / 4$ & $2 / 4$ & - & $2 / 4$ \\
\hline & & + Salvage $^{\wedge}$ & $2 / 10$ & $\begin{array}{l}16.3 \\
(7.8-24.8)\end{array}$ & $1 / 2$ & $0 / 1$ & $1 / 2$ & $1 / 2$ & - & $1 / 2$ \\
\hline & & \multicolumn{9}{|c|}{ ^Mean time to BCR (mo): 18.5 (9-28) } \\
\hline & \multirow[t]{4}{*}{$\begin{array}{l}9 \\
(n=14)\end{array}$} & $\begin{array}{l}\text { Surgery } \\
\text { Alone }\end{array}$ & $6 / 14$ & $\begin{array}{l}10.45 \\
(5.8-23.6)\end{array}$ & $5 / 6$ & $0 / 5$ & $2 / 6$ & $6 / 6$ & - & - \\
\hline & & + Adjuvant & $3 / 14$ & $\begin{array}{l}29.7 \\
(5.1-76.7)\end{array}$ & $3 / 3$ & $1 / 3$ & $2 / 3$ & $3 / 3$ & - & - \\
\hline & & + Salvage^ $^{\wedge}$ & $5 / 14$ & $\begin{array}{l}19.64 \\
(5.6-41)\end{array}$ & $4 / 5$ & $0 / 4$ & $3 / 5$ & $2 / 5$ & $1 / 5$ & $2 / 5$ \\
\hline & & \multicolumn{9}{|c|}{ ^Mean time to BCR (mo): 26 (6-48) } \\
\hline
\end{tabular}

aRadiation therapy ongoing, or no evidence disease post radiotherapy but completing prolonged course of androgen deprivation therapy.

Table 8 Outcomes of pT3b disease

\begin{tabular}{|c|c|c|c|c|c|c|c|c|c|c|}
\hline pT stage & $\begin{array}{l}\text { Gleason's } \\
\text { score }\end{array}$ & \multicolumn{2}{|l|}{ Treatment } & Mean PSA & PLND & $\begin{array}{l}\text { N1 status } \\
\text { (of PLND) }\end{array}$ & $\begin{array}{l}\text { PSM } \\
\text { (R1) }\end{array}$ & $\begin{array}{l}\text { Disease- } \\
\text { free }\end{array}$ & $\begin{array}{l}\text { Alive } \\
\text { with } \\
\text { disease }\end{array}$ & $\begin{array}{l}\text { Treatment } \\
\text { ongoing }^{\mathrm{a}}\end{array}$ \\
\hline \multirow{12}{*}{$\begin{array}{l}\text { T3b } \\
(n=30)\end{array}$} & \multirow{4}{*}{$\begin{array}{l}7 \\
(n=13)\end{array}$} & Surgery alone & $4 / 13$ & $13.03(5.6-26)$ & $2 / 4$ & $0 / 2$ & $1 / 4$ & $4 / 4$ & - & - \\
\hline & & + Adjuvant & $7 / 13$ & $9.66(2.54-19.4)$ & $5 / 7$ & $2 / 5$ & $5 / 7$ & $4 / 7$ & $2 / 7$ & $1 / 7$ \\
\hline & & + Salvage $^{\wedge}$ & $2 / 13$ & $19(14-24)$ & $2 / 2$ & $1 / 2$ & $0 / 2$ & $1 / 2$ & - & $1 / 2$ \\
\hline & & \multicolumn{9}{|c|}{ ^Mean time to BCR (mo): $8(6-10)$} \\
\hline & \multirow{4}{*}{$\begin{array}{l}8 \\
(n=8)\end{array}$} & Surgery alone & $2 / 8$ & $14.15(10.3-18)$ & $1 / 2$ & $1 / 1$ & $1 / 2$ & $2 / 2$ & - & - \\
\hline & & + Adjuvant & $5 / 8$ & $6.738(3.9-12.2)$ & $5 / 5$ & $3 / 5$ & $2 / 5$ & $3 / 5$ & $1 / 5$ & $1 / 5$ \\
\hline & & + Salvage $^{\wedge}$ & $1 / 8$ & 30 & $1 / 1$ & $0 / 1$ & $0 / 1$ & - & - & $1 / 1$ \\
\hline & & \multicolumn{9}{|c|}{${ }^{\wedge}$ Mean time to BCR (mo): 19} \\
\hline & \multirow{4}{*}{$\begin{array}{l}9 \\
(n=9)\end{array}$} & Surgery alone & $2 / 9$ & $8.2(6-10.4)$ & $2 / 2$ & $0 / 2$ & $0 / 2$ & $2 / 2$ & - & - \\
\hline & & + Adjuvant & $6 / 9$ & $16.18(5.5-28)$ & $6 / 6$ & $3 / 6$ & $4 / 6$ & $4 / 6$ & - & $2 / 6$ \\
\hline & & + Salvage $^{\wedge}$ & $1 / 9$ & 13 & $1 / 1$ & $0 / 1$ & $1 / 1$ & - & $1 / 1$ & - \\
\hline & & \multicolumn{9}{|c|}{${ }^{\wedge}$ Mean time to BCR (mo): 19} \\
\hline
\end{tabular}

aRadiation therapy ongoing, or no evidence disease post radiotherapy but completing prolonged course of androgen deprivation therapy.

rate of 8.3 to $40 \% .^{17-22}$ Of 263 patients with available pre- and postoperative detailed histopathology available, we found an overall Gleason's upgrade rate of $16.35 \%$ (43/263) which is lower than that quoted. This may be reassuring for patients on AS protocols, although we acknowledge the numbers of Glea- son's score 6 disease are low in this surgical cohort. Of patients upgraded in our cohort, the largest single group were those with Gleason's $7(3+4)$ carcinoma on diagnostic TRUS biopsy (17/43, 39.5\%).This differs from recent findings by Athanazio et al in a large Canadian study $(n=2,529)$ where Gleason's 6 to 7 


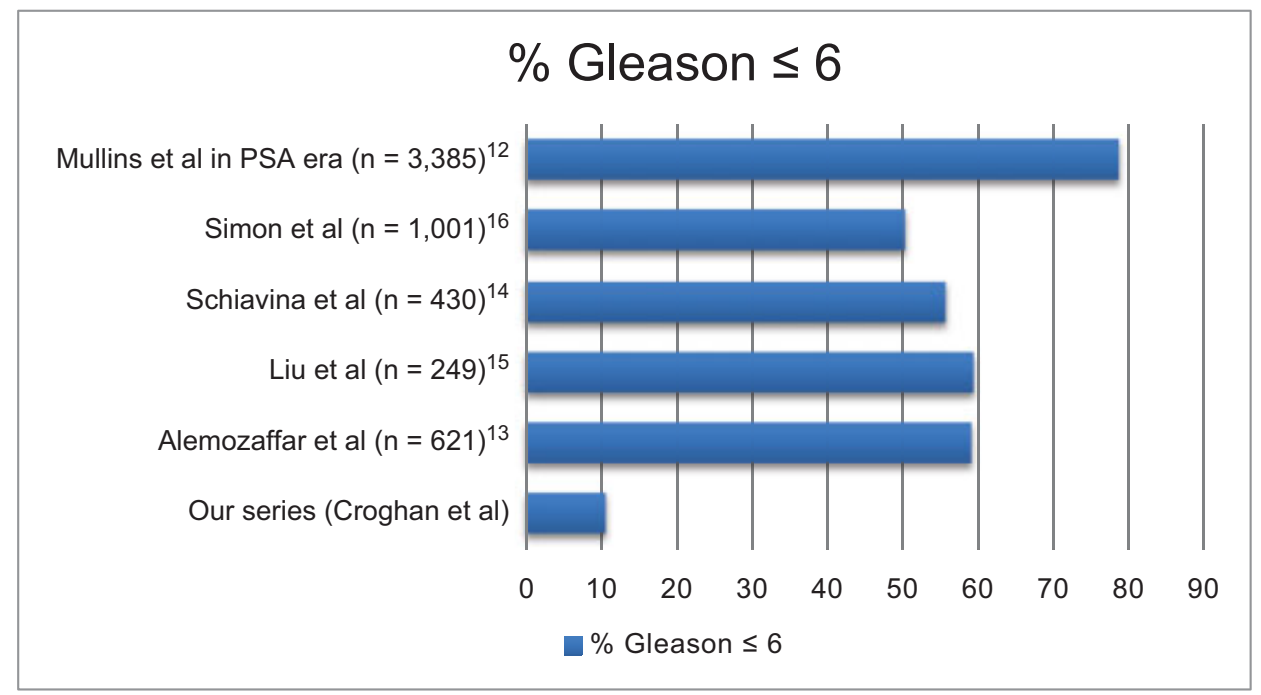

Fig. 1 Proportion of patients in radical prostatectomy series with Gleason's score $\leq 6$ disease

$(3+4)$ was the most common alteration in final histology. ${ }^{20}$ We noted a $27 \%(71 / 263)$ downgrade rate which is within the range reported. While our specimens are reported as "overall Gleason's score (components)," in acknowledgement of the Gleason's grades incorporated at the 2014 International Society of Urological Pathology (ISUP) consensus conference, ${ }^{23}$ we considered Gleason's $7(3+4)$ and Gleason's $7(4+3)$ as different grade groups and documented changes between these categories as upgraded or downgraded accordingly.

On histopathological review of the prostatectomy specimen, 170 patients (64.15\%) had pT2 disease and 95 patients (35.85\%) had pT3 disease. A higher proportion of our patients had PT3 disease than those reported in several large U.S. ${ }^{13,24}$ and European ${ }^{25,26}$ studies analyzing open RRP data, although lower than those recorded in one Italian study ${ }^{14}$ (-Fig. 2). This trend toward more locally advanced disease may be related to higher proportions of intermediate and high-risk disease as determined on biopsy Gleason's scoring seen in our patient population.

Much debate surrounds the topic of lymphadenectomy at surgery for prostate cancer. While new approaches, such as sentinel lymph node biopsy may alter the future horizon, ${ }^{27}$ pelvic lymph node dissection (PLND) remains the current gold standard approach to nodal staging, with pN1 status an

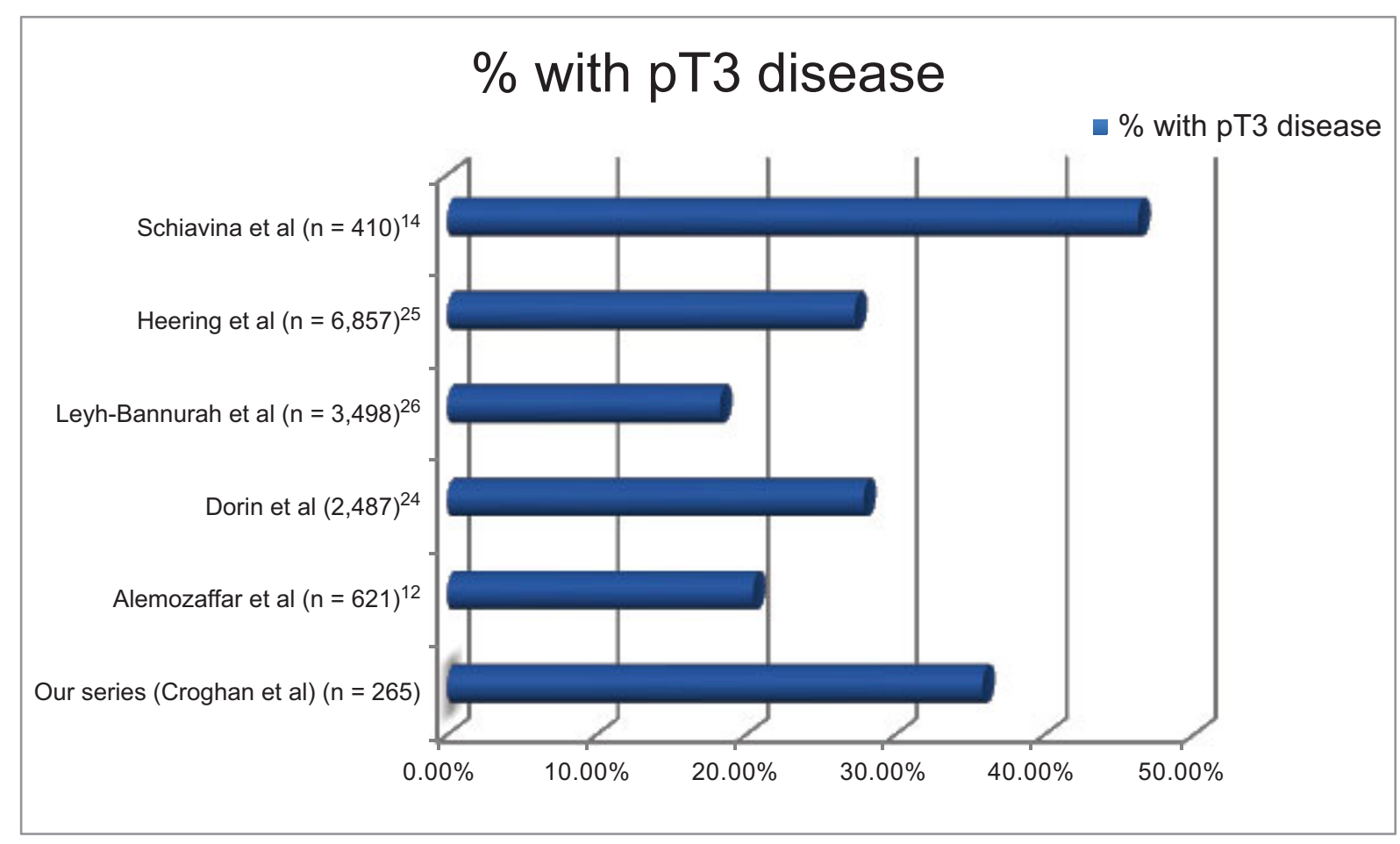

Fig. 2 Proportion of patients in radical prostatectomy series with pT3 disease 
independent predictor of disease recurrence in prostate cancer. ${ }^{28,29}$ We performed PLND guided largely by a preoperative MSKCC nomogram predicted rate of lymph node involvement of $>5 \%$ as is still the threshold recommended by EAU (European Association of Urology) guidelines. ${ }^{30} \mathrm{We}$ ultimately had an overall rate of PLND of 44.25\% (118/265). Reports of overall rates of PLND performed in RRP populations vary greatly in the literature (26.34-100\%) ${ }^{12,13,31}$ likely a result of differing proportions of high-risk disease, local policies, and the existence of a variety of nomograms and guidance sources, with the National Comprehensive Cancer Network (NCCN) guidelines ${ }^{32}$ and d'Amico risk stratification, ${ }^{33}$ for example, also frequently used. Of patients undergoing pelvic lymph node dissection, our $11.86 \%$ (14/118) detection rate of nodal metastases is higher than that reported in other studies (reported rates range: 3.4-9.65\%) $12-14,31,34$ This may reflect both higher proportions of more aggressive or locally advanced disease in this cohort compared with that of other series, as discussed above, and also a lower overall PLND rate suggesting a more stringent criteria for proceeding to nodal dissection. We noted no complications specific to lymph node dissection. During the study period, routine protocol was to perform a standard bilateral nodal dissection, with extended dissections (ePLND) performed in selected cases. We are now moving toward extended pelvic lymph node dissection (ePLND) as the standard of care.

Eighteen patients whose final histology was N0 or Nx with a clear surgical margin had a biochemical recurrence. Of this subgroup $11 / 18(61.12 \%)$ are disease-free postsalvage therapy, 2/18 (11.12\%) alive with disease and 5/18 (27.78\%) continue to undergo treatment. Mean preoperative PSA was 12.22 (range: 4-30) which was higher than the mean PSA for all patients (9.46). Of the18 patients, 9 (50\%) had high-risk Gleason's 8 or 9 disease, and the remainder Gleason's 7 disease. Again, 8/18 (44.45\%) had pT3 disease (T3a in $5 / 8$ and T3b in 3/8), all of whom underwent PLND and were staged pN0. Furthermore, 10/18 had pT2 disease (pT2c in 9/ 10), 5/10 underwent PLND and were staged N0, and 5/10 did not undergo PLND. It is unclear why this cohort experienced biochemical recurrence (BCR), although one possible explanation is that patients harbored low volume nodal metastases in nodes that were not retrieved at PLND. The number of nodes retrieved in the 13 patients in this cohort who underwent PLND (mean: 6.7 [2-26]; median 4 nodes) was similar to that in our overall study population but we acknowledge higher reported nodal retrieval in some studies. ${ }^{34}$ We plan to re-evaluate rates of recurrence in pNORO patients having implemented ePLND to explore this hypothesis.

PSMs have been shown to be independently associated with increased rates of biochemical recurrence, ${ }^{35-38}$ although their influence on prostate cancer specific mortality is debated. ${ }^{39}$ Our overall rate of margin positivity was $26.79 \%(71 / 265)$. Overall rates reported in the literature vary greatly (6.7-45.5\%), ${ }^{12,13,40-42}$ presumably in part due to differing rates of extra capsular extension between studied cohorts. Assessing surgical margins relative to pathological
T-stage, we found a PSM rate of $15.2 \%(26 / 170)$ in T2 disease, and $47.37 \%$ (45/95) in T3 disease. This compares to literature reported rates of margin positivity in $6.8-34.24 \%$ of patients with pT2 disease, and in $23-71.8 \%$ of patients with pT3 disease. ${ }^{14,35,37,41}$

Of patients with PSMs, 33.8\% (24/71) received adjuvant therapy following MDT discussion. In the later years of the study period, adjuvant therapy was administered if further high-risk features in addition to a PSM were present. Of those managed by close clinical and biochemical follow-up as opposed to adjuvant therapy, 14/47 (29.8\%) had biochemical recurrence and were referred for salvage therapy and 33/47 (70.21\%) were disease-free with no additional treatment at last follow-up. While follow-up is not yet adequate to draw definitive conclusions, we feel that PSMs alone should not prompt automatic administration of adjuvant therapy, and evidence from other experiences would support this. ${ }^{43}$

Our results found 243 patients to have completed treatment and have available follow-up data. Of these, 238 (97.9\%) were disease-free at last follow-up. Overall, 238/ $265(89.81 \%)$ of patients were disease-free at the last follow-up (mean 32.24 months), of whom 24/238 (10.08\%) had received adjuvant and 17/238 (7.14\%) received salvage radiotherapy. Adjuvant/salvage treatment was ongoing in $19 / 265(7.17 \%)$ of patients, two patients died of unrelated causes, one patient was lost to follow-up and five patients were alive with incurable disease. No patients in this series had died from prostate cancer, although we acknowledge follow-up is short for this outcome. Heterogeneity of populations and disease, variable definitions of biochemical recurrence, and differing practices in administration of adjuvant and salvage radiotherapy make outcomes difficult to compare between studies. Nonetheless, our results to date seem broadly similar to those published in the literature. Early outcomes of anatomical open RRP reported by Catalona et al $(n=925)$ suggest an overall 5year progression-free survival probability of $78 \%{ }^{44}$ More recent outcomes reported post RRP include those of Alemozaffar et al (3-year recurrence-free survival of $89.9 \%$, $n=493){ }^{13}$ Dorin et al $(n=2487$, biochemical recurrence in $11 \%$ and clinical recurrence in $3.7 \%$ at median follow-up 7.2 years), ${ }^{24}$ and Mullins et al $(n=4,478$, biochemical recurrence in 749 [16.9\%] and local recurrence in 123 [2.8\%] at mean 10 years of follow-up [range: 1-29]). Irish outcomes with RALP ( $n=125)$ have shown a biochemical free survival of $92 \%$ at 1 year follow-up. ${ }^{10}$ We defined BCR as the finding of two PSA readings $\geq 0.05 \mathrm{ng} / \mathrm{mL}$ and demonstrating a rising trend. This is a lower threshold than used by other authors who stipulate, for example, levels of $\geq 0.2 \mathrm{ng} / \mathrm{mL}^{12,35,43}$ or higher ${ }^{37}$ before declaring BCR. We would typically refer patients fitting our definition for early salvage radiotherapy and therefore have defined BCR as such.

We acknowledge several limitations to our study. Our follow-up data are insufficient to capture cases of late biochemical recurrence, as is a recognized phenomenon. ${ }^{45,46}$ For this reason, we keep our patients on annual PSA surveillance as a lifelong measure once they are disease-free for 5 years. Our 
posttreatment follow-up is further limited in the salvage radiotherapy subgroup due the latency to biochemical recurrence and further time to treatment completion within the study period. We did not record blood loss, transfusion rates, or operative time as these were not uniformly recorded in the computerized records across the hospital sites. Functional outcomes were not assessed. We recognize this as an inherent study weakness; however, these were not recorded in a standardized fashion during the study period and we feel retrospective evaluation of them would therefore lack accuracy. We therefore focused on our primary outcome of oncological results.

\section{Conclusion}

Good oncological outcomes of RRP are seen in this 5-year review with the majority of patients experiencing biochemical-free survival at most recent follow-up. This study adds Irish data to the international literature on prostate cancer disease characteristics in a selected surgical cohort and on outcomes of open radical prostatectomy.

\section{Financial Support}

None

\section{References}

1 The National Cancer Registry. Cancer in Ireland 1994-2014: annual report of the National Cancer Registry;2016. Available from: https://www.ncri.ie/publications/statistical-reports/cancer-ireland-1994-2014-annual-report-national-cancer-registry. Accessed January 16, 2018

2 Ferlay J, Steliarova-Foucher E, Lortet-Tieulent J, et al. Cancer incidence and mortality patterns in Europe: estimates for 40 countries in 2012. Eur J Cancer 2013;49(06):1374-1403

3 The National Cancer Registry. Cancer factsheet: prostate;2015. Available from: https://www.ncri.ie/sites/ncri/files/factsheets/ Factsheet\%20prostate.pdf. Accessed January 16, 2018

4 Oon SF, Cullen IM, Moran D, et al. The effect of a rapid access prostate cancer clinic on prostate cancer patient and disease characteristics, primary treatment and surgical workload. Ir J Med Sci 2014;183 (02):241-247

5 The Second National Cancer Forum. A strategy for cancer control in Ireland;2006. Available from: https://www.screeningservice. ie/publications/CancerControlStrategy2006.pdf. Accessed January 4, 2018

6 Stephenson AJ, Scardino PT, Eastham JA, et al. Preoperative nomogram predicting the 10 -year probability of prostate cancer recurrence after radical prostatectomy. J Natl Cancer Inst 2006;98 (10):715-717

7 Tan PH, Cheng L, Srigley JR, et al; ISUP Prostate Cancer Group. International Society of Urological Pathology (ISUP) consensus conference on handling and staging of radical prostatectomy specimens. Working group 5: surgical margins. Mod Pathol 2011;24(01):48-57

8 Babaian K, Truong M, Cetnar J, et al. Analysis of urological procedures in men who died from prostate cancer using a population-based approach. BJU Int 2013;111(3, Pt B):E65-E70

9 Lake AM, He C, Wood DP Jr. Focal positive surgical margins decrease disease-free survival after radical prostatectomy even in organ-confined disease. Urology 2010;76(05):1212-1216

10 Bouchier-Hayes DM, Clancy KX, Canavan K, O'Malley PJ. Initial consecutive 125 cases of robotic assisted laparoscopic radical prostatectomy performed in Ireland's first robotic radical prostatectomy centre. Ir J Med Sci 2012;181(01):21-25

11 Yaxley JW, Coughlin GD, Chambers SK, et al. Robot-assisted laparoscopic prostatectomy versus open radical retropubic prostatectomy: early outcomes from a randomised controlled phase 3 study. Lancet 2016;388(10049):1057-1066

12 Mullins JK, Feng Z, Trock BJ, Epstein JI, Walsh PC, Loeb S. The impact of anatomical radical retropubic prostatectomy on cancer control: the 30-year anniversary. J Urol 2012;188(06):2219-2224

13 Alemozaffar M, Sanda M, Yecies D, Mucci LA, Stampfer MJ, Kenfield SA. Benchmarks for operative outcomes of robotic and open radical prostatectomy: results from the health professionals follow-up study. Eur Urol 2015;67(03):432-438

14 Schiavina R, Borghesi M, Dababneh H, et al. Survival, continence and potency (SCP) recovery after radical retropubic prostatectomy: a long-term combined evaluation of surgical outcomes. Eur J Surg Oncol 2014;40(12):1716-1723

15 Liu XJ, Liu L, Chang K, Ye DW, Zheng YF, Yao XD. Risk factors of perioperative complications in patients undergoing radical retropubic prostatectomy: a ten-year experience. J Huazhong Univ Sci Technolog Med Sci 2017;37(03):379-383

16 Simon RM, Howard LE, Moreira DM, et al. Predictors of operative time during radical retropubic prostatectomy and robot-assisted laparoscopic prostatectomy. Int J Urol 2017;24(08):618-623

17 Thomas C, Pfirrmann K, Pieles F, et al. Predictors for clinically relevant Gleason score upgrade in patients undergoing radical prostatectomy. BJU Int 2012;109(02):214-219

18 Sfoungaristos S, Perimenis P. Clinical and pathological variables that predict changes in tumour grade after radical prostatectomy in patients with prostate cancer. Can Urol Assoc J 2013;7(1,2): E93-E97

19 Mortezavi A, Keller EX, Poyet C, et al. Clinical impact of prostate biopsy undergrading in an academic and community setting. World J Urol 2016;34(10):1481-1490

20 Athanazio D, Gotto G, Shea-Budgell M, Yilmaz A, Trpkov K. Global Gleason grade groups in prostate cancer: concordance of biopsy and radical prostatectomy grades and predictors of upgrade and downgrade. Histopathology 2017;70(07):1098-1106

21 Pourmand G, Gooran S, Hossieni SR, et al. Correlation of preoperative and radical prostatectomy gleason score: examining the predictors of upgrade and downgrade results. Acta Med Iran 2017;55(04):249-253

22 Hsieh TF, Chang $\mathrm{CH}$, Chen WC, Chou CL, Chen CC, Wu HC. Correlation of Gleason scores between needle-core biopsy and radical prostatectomy specimens in patients with prostate cancer. J Chin Med Assoc 2005;68(04):167-171

23 Epstein JI, Egevad L, Amin MB, Delahunt B, Srigley JR, Humphrey PA; Grading Committee. The 2014 International Society of Urological Pathology (ISUP) consensus conference on gleason grading of prostatic carcinoma: definition of grading patterns and proposal for a new grading system. Am J Surg Pathol 2016;40(02): 244-252

24 Dorin RP, Daneshmand S, Lassoff MA, Cai J, Skinner DG, Lieskovsky G. Long-term outcomes of open radical retropubic prostatectomy for clinically localized prostate cancer in the prostate-specific antigen era. Urology 2012;79(03):626-631

25 Heering M, Berg KD, Brasso K, Iversen P, Røder MA. Radical prostatectomy in Denmark: survival analysis and temporal trends in clinicopathological parameters with up to 20 years of followup. Surg Oncol 2017;26(01):21-27

26 Leyh-Bannurah SR, Karakiewicz PI, Dell'Oglio P, et al. Comparison of 11 active surveillance protocols in contemporary european men treated with radical prostatectomy. Clin Genitourin Cancer 2017;16(01):e141-e149

27 van der Poel HG, Wit EM, Acar C, et al; Sentinel Node Prostate Cancer Consensus Panel Group members. Sentinel node biopsy for prostate cancer: report from a consensus panel meeting. BJU Int 2017;120(02):204-211 
28 Bianchi L, Gandaglia G, Fossati N, et al. Pelvic lymph node dissection in prostate cancer: indications, extent and tailored approaches. Urologia 2017;84(01):9-19

29 De Vergie S, Gaschignard N, Baron M, et al. [Long-term outcomes of prostate cancer patients with lymph nodes metastasis after radical prostatectomy and pelvic lymph node dissection]. Prog Urol 2018;28(01):25-31

30 Mottet N, Bellmunt J, Bolla M, et al. EAU-ESTRO-SIOG guidelines on prostate cancer. part 1: screening, diagnosis, and local treatment with curative intent. Eur Urol 2017;71(04): 618-629

31 Yaxley JW, Dagher J, Delahunt B, Egevad L, Srigley J, Samaratunga $\mathrm{H}$. Reconsidering the role of pelvic lymph node dissection with radical prostatectomy for prostate cancer in an era of improving radiological staging techniques. World J Urol 2018; 36(01):15-20

32 National Comprehensive Cancer Network2017. Available from: https://www.nccn.org/professionals/physician_gls/PDF/prostate. pdf. Accessed January 4, 2018

33 D'Amico AV, Whittington R, Malkowicz SB, et al. Biochemical outcome after radical prostatectomy, external beam radiation therapy, or interstitial radiation therapy for clinically localized prostate cancer. JAMA 1998;280(11):969-974

34 Wang EH, Yu JB, Gross CP, et al. Association between surgeon and hospital characteristics and lymph node counts from radical prostatectomy and pelvic lymph node dissection. Urology 2015; 85(04):890-895

35 Abdollah F, Sun M, Suardi N, et al. Presence of positive surgical margin in patients with organ-confined prostate cancer equals to extracapsular extension negative surgical margin. A plea for TNM staging system reclassification. Urol Oncol 2013;31(08):1497-1503

36 Karakiewicz PI, Eastham JA, Graefen M, et al. Prognostic impact of positive surgical margins in surgically treated prostate cancer: multi-institutional assessment of 5,831 patients. Urology 2005; 66(06):1245-1250
37 Swindle P, Eastham JA, Ohori M, et al. Do margins matter? The prognostic significance of positive surgical margins in radical prostatectomy specimens. J Urol 2005;174(03):903-907

38 Ohori M, Wheeler TM, Kattan MW, Goto Y, Scardino PT. Prognostic significance of positive surgical margins in radical prostatectomy specimens. J Urol 1995;154(05):1818-1824

39 Yossepowitch O, Briganti A, Eastham JA, et al. Positive surgical margins after radical prostatectomy: a systematic review and contemporary update. Eur Urol 2014;65(02):303-313

40 Mauermann J, Fradet V, Lacombe L, et al. The impact of solitary and multiple positive surgical margins on hard clinical end points in 1,712 adjuvant treatment-naive pT2-4 N0 radical prostatectomy patients. Eur Urol 2013;64(01):19-25

41 Lee JW, Ryu JH, Kim YB, Yang SO, Lee JK, Jung TY. Do positive surgical margins predict biochemical recurrence in all patients without adjuvant therapy after radical prostatectomy? Korean J Urol 2013;54(08):510-515

42 Ploussard G, Agamy MA, Alenda O, et al. Impact of positive surgical margins on prostate-specific antigen failure after radical prostatectomy in adjuvant treatment-naïve patients. BJU Int 2011;107(11):1748-1754

43 Chapin BF, Nguyen JN, Achim MF, et al. Positive margin length and highest Gleason grade of tumor at the margin predict for biochemical recurrence after radical prostatectomy in patients with organ-confined prostate cancer. Prostate Cancer Prostatic Dis 2018;21(02):221-227

44 Catalona WJ, Smith DS. 5-year tumor recurrence rates after anatomical radical retropubic prostatectomy for prostate cancer. J Urol 1994;152(5, Pt 2):1837-1842

45 Negishi T, Kuroiwa K, Hori Y, et al. Predictive factors of late biochemical recurrence after radical prostatectomy. Jpn J Clin Oncol 2017;47(03):233-238

46 Liesenfeld L, Kron M, Gschwend JE, Herkommer K. Prognostic Factors for Biochemical Recurrence More than 10 Years after Radical Prostatectomy. J Urol 2017;197(01):143-148 